\title{
Reanalysis of global terrestrial vegetation trends from MODIS products: browning or greening?
}

Yulong Zhang ${ }^{1,2^{*}}$, Conghe Song ${ }^{1,3^{*}}$, Lawrence E. Band ${ }^{1,2}, \mathrm{Ge} \mathrm{Sun}^{4}$ and Junxiang $\mathrm{Li}^{3}$

${ }^{1}$ Department of Geography, University of North Carolina, Chapel Hill, NC, USA

${ }^{2}$ Institute for the Environment, University of North Carolina, Chapel Hill, NC, USA

${ }^{3}$ School of Ecological and Environmental Sciences, East China Normal University, Shanghai, China

${ }^{4}$ Eastern Forest Environmental Threat Assessment Center, Southern Research Station, USDA Forest Service, Raleigh, NC, USA

Corresponding authors:

Yulong Zhang and Conghe Song

Department of Geography

University of North Carolina, Chapel Hill, NC 27599, USA

Tel: +1 919-843-4764

Fax: +1 919-962-1537

E-mail: ylzhang@unc.edu; csong@ email.unc.edu

Running title: browning or greening 


\begin{abstract}
Accurately monitoring global vegetation dynamics with modern remote sensing is critical for understanding the functions and processes of the biosphere and its interactions with the planetary climate. The MODerate resolution Imaging Spectroradiometer (MODIS) vegetation index (VI) product has been a primary data source for this purpose. To date, the MODIS team had released several versions of VI products that have widely used in global change studies and practical applications. In this study, we re-examined the global vegetation activity by comparing the recent MODIS Collection 6 (C6) VIs with Collection 5 (C5) VIs including Normalized Difference Vegetation Index (NDVI) and Enhanced Vegetation Index (EVI) from Terra (2001 2015) and Aqua Satellites (2003 - 2015). We found substantial differences in global vegetation trends betweenTerra-C5 and -C6 VIs, especially EVI. From 2001 to 2015, global vegetation showed a remarkable greening trend in annual EVI from the Terra-C6 $\left(0.28 \% \mathrm{yr}^{-1} ; \mathrm{P}<0.001\right)$, in contrast to the decreasing EVI trend from the Terra-C5 $\left(-0.14 \% \mathrm{yr}^{-1}, \mathrm{p}<0.01\right)$. Spatially, large portions of the browning areas in tropical regions identified by Terra-C5 VIs were not evident in Terra-C6 VIs. In contrast, the widespread greening areas in Terra-C6 VIs were consistent with Aqua-C6 VIs and GIMMS3g NDVI. Our finding of a greening Earth supports the recent studies suggesting an enhanced land carbon sink. Our study suggests that most of the vegetation browning trends detected by MODIS Terra-C5 VIs were likely caused by sensor degradation, particularly for the period after 2007. Therefore, previous studies of temporal vegetation trends based solely on Terra-C5 VIs may need to be reevaluated. Our new analysis offers the most updated understanding of the global vegetation dynamics during the past 15 years and contributes to accurately understanding the role of vegetation played in the Earth's biogeochemical and climatic systems.
\end{abstract}




\section{Keywords}

Vegetation Indices, MODIS, Collection 5 \& 6, Terra, Aqua, Browning, Greening 


\section{Introduction}

Terrestrial vegetation is a key component of the biosphere, regulating global carbon, water and energy cycles (Baldocchi et al., 2001; Law et al., 2002). Systematically monitoring global vegetation dynamics is critical to understand the basic biogeochemical processes, and their possible feedbacks to the climate system (Arneth et al., 2010; Falkowski et al., 2000), and thus improves our ability to predict, mitigate and adapt to future global climate change (Cramer et al., 2001; Sitch et al., 2008). The advent of digital optical remote sensing has revolutionized our ability to monitor such dynamics. As simple and robust measures of vegetation activity at the land surface, vegetation indices (VIs) are generally computed from remotely sensed data based on the fundamental optical characteristics of vegetation that are strongly absorptive in the red, but highly reflective in the near-infrared (NIR) regions of the solar spectrum (Rouse et al., 1974; Tucker, 1979). VI, as an integral indicator, is not only a structural parameter that relates to canopy leaf area index and leaf morphology (Carlson and Ripley, 1997), but also a physiological parameter that measures chlorophyll abundance in leaves, thus determining photosynthetic capacity and plant growth potential (Running et al., 2004).

Although numerous VIs have been developed in the past decades, one of the most widely used is the Normalized Difference Vegetation Index (NDVI) (Huete et al., 1997, 2002). The Advanced Very High Resolution Radiometer (AVHRR) sensor onboard NOAA polar orbiting satellite series produces the longest continuous record of NDVI data from July 1981 to the present (Tucker et al., 2005), such as GIMMS3g (Generation of Global Inventory Modeling and Mapping Studies 3rd Version; Pinzon and Tucker, 2014) and LTDR4 (Land Long Term Data Record 4th Version; Pedelty et al., 2007). Based on newer and more advanced sensors, several moderate-term NDVI datasets, such as SPOT-VGT (Système Pour l'Observation de la Terre 
VEGETATION; 1998 - 2014; Maisongrande et al., 2004), and MODIS (MODerate resolution Imaging Spectroradiometer; 2000 - present; Huete et al., 2002) have been produced. By combining the long-term AVHRR-based LTDR (1981 - 1999) and moderate-term MODIS (2000 - present) datasets, the Vegetation Index and Phenology Laboratory constructed a new global NDVI dataset VIP3 (Didan, 2010; Marshall et al., 2016). However, a recent evaluation study (Tian et al., 2015) showed that, except for MODIS, all the above-mentioned NDVI datasets had been compromised with temporal inconsistency for trend analysis due to sensor differences and sensor shifts between platforms (Tarnavsky et al., 2008), creating uncertainties for global vegetation analysis based on these NDVI datasets.

As the flagships of the Earth Observation System operated by US National Aeronautics and Space Administration (NASA), MODIS sensors abroad Terra and Aqua satellites have a designed life of six years, but they have been in operation since 1999 and 2002, respectively (http://modis.gsfc.nasa.gov/about/specifications.php). MODIS NDVI does not suffer from the problem of data inconsistency from multiple sensors as for the other long-term NDVI datasets. Despite being referred to as the "continuity index" of the existing AVHRR-based NDVI time series (Huete et al., 2002), MODIS NDVI with the advanced navigation system and improved radiometric sensitivity is considered to be superior to AVHRR-based NDVI (Fensholt and Proud, 2012; Huete et al., 2002). Another MODIS VI is the Enhanced Vegetation Index (EVI) that further reduces the remnant atmospheric and soil background contamination, improving sensitivity to densely vegetated areas (Huete et al., 2002). The two complementary VI datasets (NDVI and EVI) from the twin satellites of Terra and Aqua provide a unique opportunity to monitor and assess global vegetation dynamics. 
MODIS sensors have been in operation well past their design life. Before the year of 2015, NASA had released several versions of MODIS products with improving data quality. However, in the past several years, inconsistent results from Terra and Aqua were noticed in multiple MODIS Collection 5 (C5) products (e.g. ocean color (Djavidnia et al., 2010), aerosols (Levy et al., 2010), NDVI and EVI (Zhao and Running, 2011)), which were later identified to be mainly caused by sensor degradation (Lyapustin et al., 2014; Wang et al., 2012). To address this sensor problem as well as other issues, NASA initialized a comprehensive MODIS products update from C5 to Collection 6 (C6) for both Terra and Aqua in February 2015 (http://modisland.gsfc.nasa.gov/news.html) based on a new calibration approach (Lyapustin et al., 2014). The full reprocessed MODIS-C6 VI products have been released in late 2015. Compared to C5, MODIS-C6 VIs are expected to not only remove the major sensor degradation impacts (Lyapustin et al., 2014), but also implement several improvements in the VI retrieval algorithm (Didan et al., 2015). Given that the old MODIS-C5 VIs have been extensively used in global and regional vegetation dynamics studies (Seddon et al., 2016; Xu et al., 2011; Zhao and Running, 2011; Zhou et al., 2014), and will be maintained for another year in parallel with C6 (Lyapustin et al., 2014), it is important to evaluate the differences between C5 and C6 VIs. Although a recent comparative study evaluated the performance of MODIS-C6 against -C5 (Detsch et al, 2016), it was only carried out on local scale and solely on NDVI. In this study, we performed a global assessment of annual vegetation dynamics with MODIS-C5 and -C6 VIs (NDVI \& EVI) from Terra and Aqua over the period of 2001 to 2015, and further examined the climatic sensitivity of vegetation based on the updated C6 data.

\section{Materials and Methods}

\subsection{Global Datasets}


In this study, we used a series of global datasets since 2001 for analysis, including MODIS VIs (NDVI and EVI from C5 \& C6) from Terra (2001 - 2015) and Aqua (2003 - 2015), GIMMS3g NDVI (2001 - 2013), MODIS land cover (2007), land carbon budget (2001 - 2014), and CRUNCEP climate data (2001 - 2014).

\subsubsection{MODIS Vegetation Indices}

Global Monthly MODIS-Terra (MOD13C2; 2001 - 2015) and MODIS-Aqua (MYD13C2; 2003 - 2015) VI products from C5 and C6 were downloaded from NASA's Earth Observing System Data and Information System Reverb (http://reverb.echo.nasa.gov/). MODIS-Terra in 2000 and MODIS-Aqua in 2002 do not have complete year data, thus were excluded in this study. Both MOD13C2 and MYD13C2 are cloud-free spatial composites of the gridded 16-day 1-kilometer MODIS VIs, and are provided as a time-weighted monthly level-3 product projected on a 0.05 degree geographic Climate Modeling Grid (CMG) (Huete et al., 1999). Compared to C5, C6 had implemented several major improvements (Didan et al., 2015), including: 1) use of precomposited surface reflectance data derived from C6 level-1 bands, 2) modification of the constrained view angle maximum value composite, 3) an updated new robust 2-band EVI backup algorithm, 4) adjustment of the relative azimuth angle to a wider dynamic range. We extracted the monthly NDVI and EVI data from the original MODIS-Terra and MODIS-Aqua HDF data, and averaged them to the annual values. If the monthly VI value is negative, we treated it as zero during the calculation. To minimize the effects of permanent snow/ice, water body, bare land and urban on VIs, we further used MODIS land cover data (MCD12C1 C5; 0.05 degree) in 2007 to mask out all the non-vegetated areas.

\subsubsection{GIMMS3g NDVI and Land Carbon Sink Data}

Given GIMMS3g NDVI was widely used in long-term global vegetation studies, we derived 
vegetation dynamics trend from it in the study to compare with that from the MODIS VIs. The global half-monthly GIMMS3g NDVI data with a spatial resolution of 1/12 degree from 2001 to 2013 were downloaded from NASA Earth Exchange platform (http://ecocast.arc.nasa.gov/data/pub/gimms/3g.v0/). GIMMS3g NDVI was derived from the sensor of AVHRR-3 aboard the consecutive satellites of NOAA-16, -17 and -18 after 2000 (Pinzon and Tucker, 2014). The NDVI product was smoothed by filling the gaps with average seasonal profile or by spline interpolation (Pinzon and Tucker, 2014). We calculated the annual NDVI by averaging all the half-monthly values within a year. Similar to the process of MODIS VIs, the negative value of the half-monthly NDVI was set to zero. To verify global VI trends, terrestrial carbon sink data from 2001 to 2014 were also obtained from the Global Carbon Project (http://www.globalcarbonproject.org/carbonbudget/15/data.htm). The land sink here was a bookkeeping-based estimate derived as the residual of global total fossil fuel and land-use change emissions, atmosphere carbon increase and ocean carbon uptake (Quéré et al., 2015).

\subsubsection{CRU-NCEP Climate Data}

Global radiation, air temperature and precipitation from 2001 to 2014 were obtained from CRUNCEP (Version 6; http://dods.extra.cea.fr/data/p529viov/cruncep/V6_1901_2014/). CRU-NCEP climate data are the combination of the ground observation-based CRU TS 3.2 data and modelbased NCEP-NCAR Reanalysis data, which has a spatial resolution of $0.5^{\circ} \times 0.5^{\circ}$ and a temporal resolution of 6 hours (ftp://nacp.ornl.gov/synthesis/2009/frescati/model_driver/cru_ncep/analysis/readme.htm). We rescaled the 6-hourly data to annual values. 


\subsection{Analysis Methods}

Global GIMMS3g NDVI and CRU-NCEP with relative coarse spatial resolutions were resampled to the same resolution of MODIS data (i.e. $0.05^{\circ} \times 0.05^{\circ}$ ) using bilinear interpolation. To better calculate the area-weighted values, we reprojected all the above-mentioned global raster data from the Geographical Coordinate System into the equal-area Mollweide projection with a spatial resolution of $5 \times 5 \mathrm{~km}^{2}$. We computed annual global averaged values in all MODIS VIs and GIMMS3g NDVI over the vegetated area from 2001 to 2015. To investigate the spatial variation of greenness across the globe, we further calculated the pixel-by-pixel linear trends (slope and $\mathrm{P}$ value) and their trend histograms in annual Terra-VIs during the same period. We also compared the spatial-temporal differences in all VIs (Terra, Aqua, and GIMMS3g) during their overlap period (2003-2013).

It is important to note that the vegetation activity in this study was quantified by the annual averaged monthly VI, in which some monthly negative values due to snow and ice effects were treated as zero. In other words, we assumed that those negative monthly VIs over vegetated area are ecologically meaningless for vegetation dynamics analysis. Actually, annual mean VI here is equivalent to annual total effective greenness by multiplying 12 . Our treatment on masking negative VI values could not only minimize the snow/ice effects, but also provide a consistent global analysis mask for different VI datasets. In 2007, global VIs from Terra-C5 and Terra-C6 were involved in this masking operation on about $16 \%$ and $17 \%$ of vegetated pixels, respectively, which were mainly located in the high-latitude areas due to seasonal snow/ice (Fig. 1a, b; Table S1). 
The monthly CMG (i.e. 0.05 degree, or about $5600 \mathrm{~m}$ ) MODIS VI data used in this study are cloud-free products, which were generated with three different averaging schemes based on the original 16-day $1 \times 1 \mathrm{~km}^{2}$ MODIS VI data (Didan et al., 2015). Specifically, all input 1-km pixels (nominally $6 \times 6$ ) within the CMG pixel would either be all clear, all cloudy, or mixed. If all input pixels are clear, they will be all averaged to produce one output value; If the input pixels are mixed, only the clear pixels are used to produce the output value; Otherwise, if all input pixels are cloudy, the output value will be estimated from the historical records. The filled VI value is calculated from the average of high-quality data (i.e. cloud-free, nadir view pixel with no residual atmospheric contamination) in that composite period from all previous years. When all the 16-day CMG data are computed, weigh factors based on the degree of temporal overlap are applied to calculate the final monthly CMG data. During the temporal aggregation, the lowest quality assurance is used to flag the CMG pixel. Based on the entire MODIS data record, this gap filling scheme is considered to perform well to effectively fill in most cloud-contaminated pixels (Didan et al., 2015). However, for certain highly dynamic or disturbed areas, filling with historic values may introduce discrepancies and obscure the actual vegetation trend. In 2007, global VIs estimated by historic data (i.e. MODIS Pixel Reliability $=4$ ) in Terra-C5 and TerraC6 were about $11 \%$ and $12 \%$ of vegetated pixels, respectively, most of which were filled less than three months (Table S1). These pixels are mainly distributed in tropical, monsoon and boreal regions (Fig. 1c, d). 

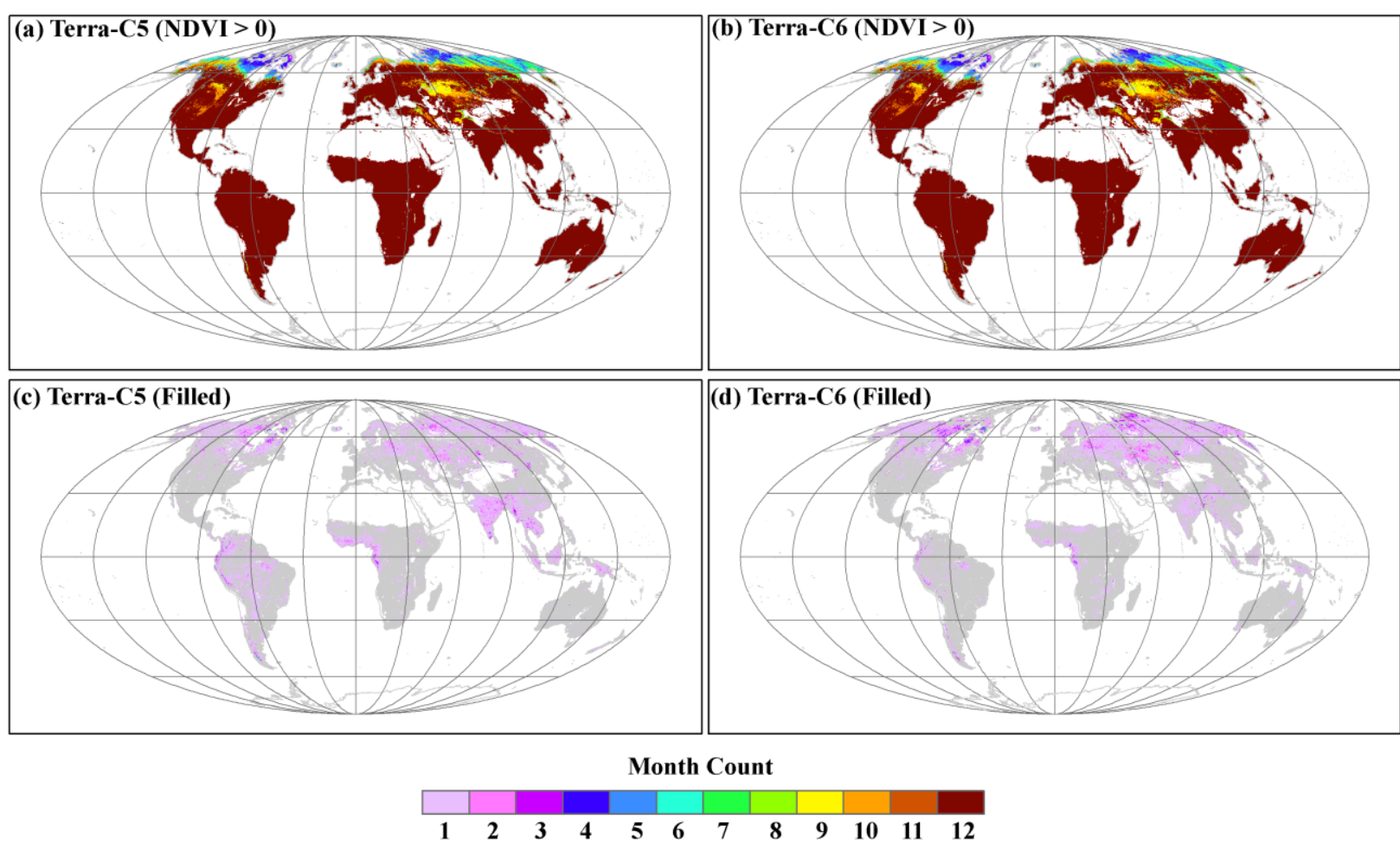

Fig. 1. Spatial patterns of data quality for Terra-C5 and Terra-C6 in 2007. (a) (b): month counts on Terra-C5 (a) and Terra-C6 (b) with monthly NDVI > 0; (c) (d): month counts on Terra-C5 (c) and Terra-C6 (d) with monthly NDVI/EVI filled by historic data due to bad quality. Non-vegetated area are masked out. The gray background in (c) and (d) indicate the vegetated area. The summary statistics are seen in Table S1.

To evaluate the robustness of annual VI (hereafter indicating annual averaged monthly VI) trend, we calculated annual maximum VI (hereafter indicating annual maximum monthly VI), and analyzed its annual trend in Terra-C5 and Terra-C6. Annual maximum VI is expected to be least influenced by the effects of snow/ice and clouds, and have a close relationship with annual VI. A desert site is considered to be "pseudo-invariant", and theoretically has no long-term trend in its reflectance, thus no temporal trend is expected (Wang et al., 2012). In this study, we selected a desert site in Egypt $\left(27.12^{\circ} \mathrm{N}, 26.10^{\circ} \mathrm{E}\right.$; http://calval.cr.usgs.gov/rstresources/sites_catalog/radiometric-sites/egypt-1/) to check whether MODIS-C6 have effectively 
corrected the sensor degradation effect. We analyzed the long-term monthly trends in VIs and relevant level-1reflectance bands (i.e. Red, Blue and NIR) from Terra-C5 and -C6 products (i.e. MOD13C2) over this site. To test the presence or absence of sensor degradation effect over large areas, we further compared the annual EVI trends from Terra and Aqua (C5 \& C6) over a vast arid desert in northern Africa and western Asia $\left(7.169^{\circ} \mathrm{N} \sim 39.249^{\circ} \mathrm{N} ;-27.174^{\circ} \mathrm{W} \sim 59.491^{\circ} \mathrm{E}\right)$.

To investigate the sensitivity of vegetation to climate variations, we examined the partial correlations between annual Terra-C6 EVI and three key climate factors (i.e. annual total radiation, mean air temperature and total precipitation) from 2001 to 2014. The year 2015 was not used due to the unavailability of the CRU-NCEP climate data. The partial correlation for each climate factor was computed by controlling the other two factors (Cohen et al. 2013). The ttest $(\mathrm{df}=\mathrm{n}-2-1)$ was used to examine the significance level of these partial correlations. To quantify the total climate control on greenness variations, we further calculated the multiple correlation between annual Terra-C6 EVI and the three climate factors. The multiple correlation is a measure of how well a given variable can be explained using a linear function of a set of independent variables (Cohen et al. 2013). The square of the multiple correlation is known as coefficient of determination (or $\mathrm{R}^{2}$ ), which indicates the proportion of the variance in the dependent variable that is explained by the independent variables (Cohen et al. 2013).

\section{Results}

\subsection{Temporal Differences in Global Vegetation Trends}

The Terra-C5 and Terra-C6 VIs showed significantly different trends during the study period (Fig. 2). For Terra-C6, annual global NDVI and EVI both showed significant increasing trends 
from 2001 to 2015 ( $0.22 \% \mathrm{yr}^{-1}$ for NDVI, $\mathrm{P}<0.001 ; 0.28 \% \mathrm{yr}^{-1}$ for EVI, $\mathrm{P}<0.001$; Fig. 2; Table 1). However, for Terra-C5, annual global NDVI showed no particular trend $\left(0.01 \% \mathrm{yr}^{-1}, \mathrm{P}=0.66\right.$; Fig. 2a), while EVI showed significant decreasing trend $\left(-0.14 \% \mathrm{yr}^{-1}, \mathrm{P}<0.01\right.$; Fig. $\left.2 \mathrm{~b}\right)$. The multi-year averaged value of global NDVI from Terra-C6 is slightly higher $(\sim 0.7 \%)$ than that from Terra-C5 (Table 1). We also noted that the discrepancies of the two NDVI products were relatively small prior to 2007, but became substantially larger afterwards (Fig. 2a). In contrast, the multi-year averaged global EVI from Terra-C6 was lower $(\sim-1.5 \%)$ than that from Terra-C5 (Table 1). Their annual discrepancies were especially pronounced during the first eight years (2001 to 2008; Fig. 2b). However, compared to Terra-C6, Terra-C5 EVI had a sharp decline after 2007 (Fig. 2b).


Fig. 2. Comparisons of annual changes of global average NDVI (a) and EVI (b) over vegetated area from 2001 to 2015 among MODIS products. Annual GIMMS3g NDVI and land carbon sink from global carbon budget were included in (a) and (b), respectively. 
Table 1. Summary statistics on annual changes in NDVI and EVI from MODIS Terra products (C5 \& C6) from 2001 to 2015 on the global scale.

\begin{tabular}{ccccc}
\hline $\begin{array}{c}\text { Vegetation } \\
\text { Index }\end{array}$ & $\begin{array}{c}\text { Terra-NDVI } \\
\text { (C5) }\end{array}$ & $\begin{array}{c}\text { Terra-NDVI } \\
\text { (C6) }\end{array}$ & $\begin{array}{c}\text { Terra-EVI } \\
\text { (C5) }\end{array}$ & $\begin{array}{c}\text { Terra-EVI } \\
\text { (C6) }\end{array}$ \\
\hline Mean $^{\mathrm{a}}$ & 0.451 & 0.454 & 0.272 & 0.268 \\
STD $^{\mathrm{b}}$ & 0.0024 & 0.0047 & 0.0025 & 0.0036 \\
Trend $^{\mathrm{c}}$ & 0.00007 & 0.00098 & -0.00039 & 0.00076 \\
$\mathrm{P} \mathrm{value}^{\mathrm{d}}$ & $(0.01 \%)$ & $(0.22 \%)$ & $(-0.14 \%)$ & $(0.28 \%)$ \\
$+^{\mathrm{e}}$ & 0.66 & 0.00 & 0.00 & 0.00 \\
${ }^{\mathrm{f}}$ & $52.2 \%$ & $70.7 \%$ & $40.1 \%$ & $72.2 \%$ \\
$++^{\mathrm{g}}$ & $47.8 \%$ & $29.3 \%$ & $59.9 \%$ & $27.8 \%$ \\
$--^{\mathrm{h}}$ & $11.4 \%$ & $23.1 \%$ & $8.1 \%$ & $22.8 \%$ \\
\hline
\end{tabular}

a: global averaged mean over vegetated area; b: temporal standard deviation; c: slope of linear trend on annual scale; the parenthesis is the slope relative to the mean; d: significance level for the trend; e: greening area with linear trend great than 0; f: browning area with linear trend less than 0; g: significantly greening area with $\mathrm{P}<0.05$; h: significantly browning area with $\mathrm{P}<0.05$

Compared to Terra, Aqua exhibited much more consistent trends in annual VIs between C5 and C6 (Fig. 2; Table S2). From 2003 to 2015, Aqua-C5 and Aqua-C6 VIs showed strong correlations both in annual global NDVI $(\mathrm{R}=0.96, \mathrm{P}<0.001)$ and $\mathrm{EVI}(\mathrm{R}=0.95, \mathrm{P}<0.001)$. However, Terra-C5 and Terra-C6 were poorly correlated in annual NDVI $(\mathrm{R}=0.25, \mathrm{P}=0.41)$, and even significant negative correlation in EVI $(\mathrm{R}=-0.58, \mathrm{P}=0.04)$. Overall, from $\mathrm{C} 5$ to $\mathrm{C} 6$, annual trend in global averaged NDVI (EVI) from Terra increased from $-0.01 \% \mathrm{yr}^{-1}\left(-0.18 \% \mathrm{yr}^{-1}\right)$ to $0.21 \% \mathrm{yr}^{-1}\left(0.27 \% \mathrm{yr}^{-1}\right)$, while the trend in annual NDVI (EVI) from Aqua increased from $0.14 \%$ $\mathrm{yr}^{-1}\left(0.16 \% \mathrm{yr}^{-1}\right)$ to $0.17 \% \mathrm{yr}^{-1}\left(0.27 \% \mathrm{yr}^{-1}\right)$. Similar with Terra, Aqua showed a higher multi-year mean of annual global NDVI, but a lower value of EVI in C6 compared to C5 (Fig. 2). For the cross-sensor comparison, Terra and Aqua showed much higher agreements in VIs from C6 
compared to C5 (Fig. 2). From 2003 to 2015, Terra-C5 and Aqua-C5 had poor correlation in annual NDVI $(\mathrm{R}=0.24, \mathrm{P}=0.43)$ and even significant negative correlation in annual EVI $(\mathrm{R}=$ $0.55, \mathrm{P}=0.05)$. In contrast, Terra-C6 and Aqua-C6 were significantly correlated for NDVI $(\mathrm{R}=$ $0.90, \mathrm{P}<0.001)$ and EVI $(\mathrm{R}=0.95, \mathrm{P}<0.001)$.

During the overlap period of 2003 to 2013, global GIMMS3g NDVI was generally consistent with the inter-annual variations in NDVI from Terra-C6 $(\mathrm{R}=0.75, \mathrm{P}=0.01)$ and Aqua-C6 $(\mathrm{R}=$ $0.70, \mathrm{P}=0.02$ ). However, compared to MODIS-C6 NDVIs, GIMMS3g NDVI had higher annual mean values with some abrupt variations in the initial years (i.e. 2001 to 2003) and the last few years (i.e. 2009 - 2013) (Fig. 2a). The Global Carbon Project (Quéré et al., 2015) reported that the land had the highest carbon sink in the year of 2014 since 2000, which corresponded to the highest annual EVI from both Terra-C6 and Aqua-C6 (Fig. 2b). From 2001 to 2014, annual EVI from Terra-C6 had a significant correlation with annual land carbon sink $(\mathrm{R}=0.68, \mathrm{P}=0.01$; Fig. $2 b)$.

We analyzed the variations and trends in annual maximum VIs from MODIS-Terra, which showed high consistence with annual VIs (Fig. 3a, b). From 2001 to 2015, annual maximum Terra-C6 NDVI and EVI both showed extremely significant increasing trends $\left(0.15 \% \mathrm{yr}^{-1}, \mathrm{p}<\right.$ 0.001, Fig. 3a; 0.23\% $\mathrm{yr}^{-1}, \mathrm{P}<0.001$, Fig. 3b), which explained $94.3 \%(\mathrm{P}<0.001)$ and $93.1 \%(\mathrm{P}$ $<0.001$ ) of variations in annual average NDVI and EVI, respectively. Meanwhile, both annual maximum NDVI and EVI from Terra-C5 showed decreasing trends (Fig. 3a, b). At the desert site in Egypt, Terra-C6 showed no particular trends (i.e. P > 0.05) in MODIS surface reflectance that used to calculate VIs (i.e. red, blue and NIR bands) during the study period (Fig. 3c). In contrast, all the three bands showed extremely significant decreasing trends for MODIS Terra-C5 (Fig. 
3c). Consequently, monthly EVI at the desert site showed a clear downward trend for Terra-C5 ($\left.0.036 \% \mathrm{mon}^{-1}, \mathrm{P}<0.001\right)$, while insignificant for Terra-C6 (0.005\% $\left.\mathrm{mon}^{-1}, \mathrm{P}=0.347\right)$ (Fig. 3d).
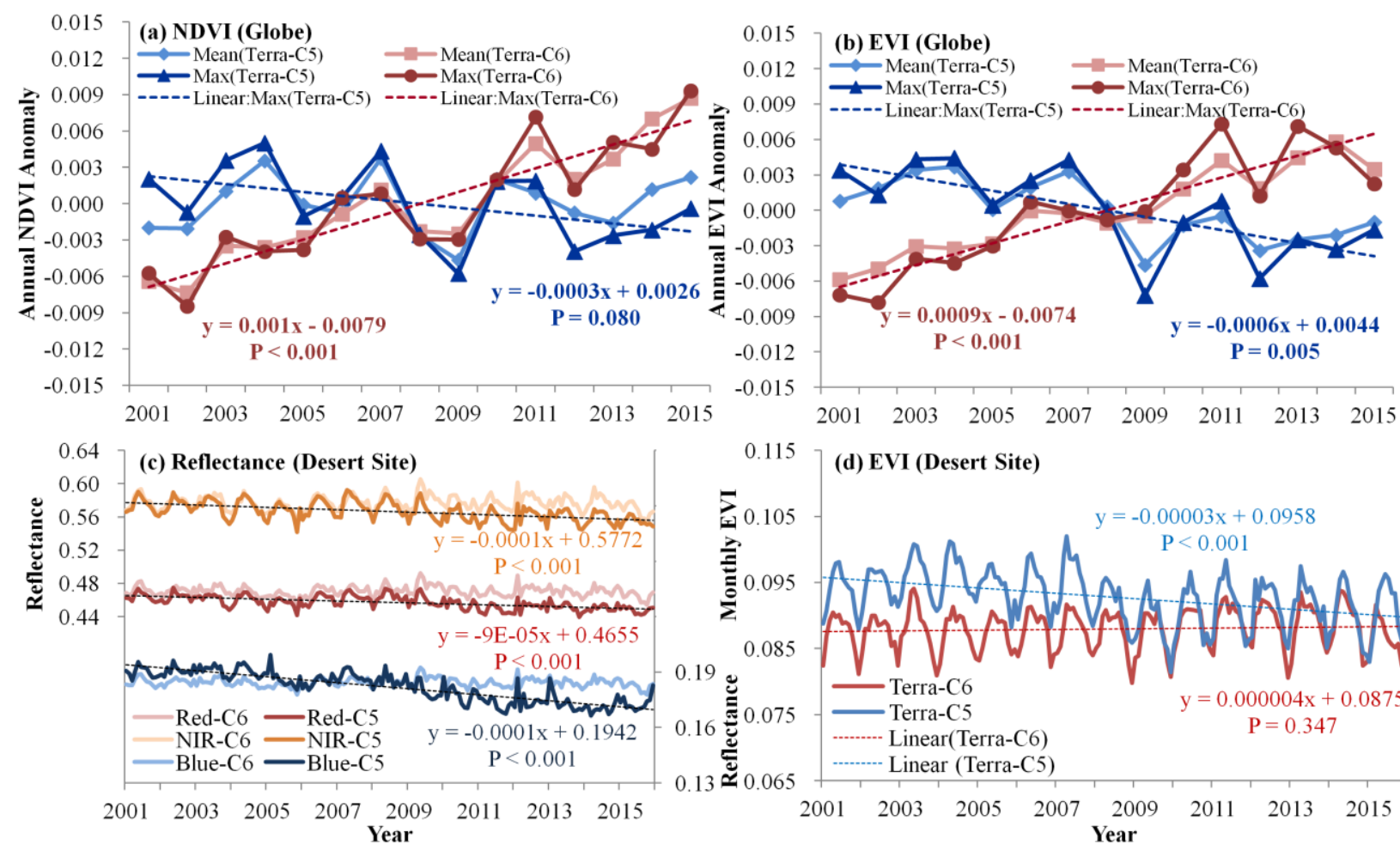

(d) EVI (Desert Site)

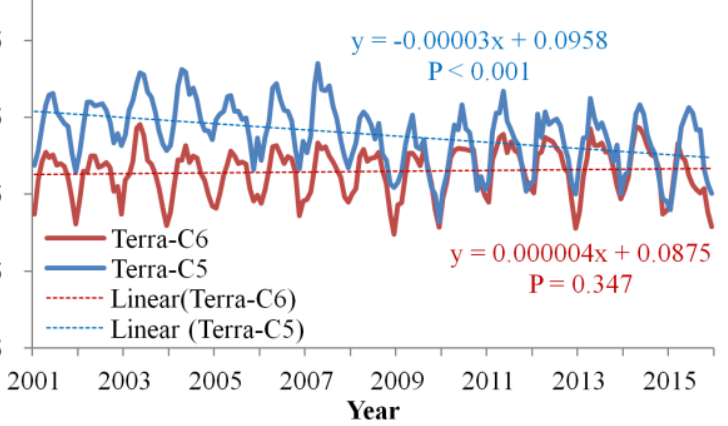

Fig. 3. Comparisons between Terra-C5 and Terra-C6 in inter-annual trends of global averaged maximum NDVI (a) and EVI (b), and monthly surface reflectance (c) and EVI (d) at a desert site in Egypt from 2001 to 2015. The annual anomalies in (a) and (b) are relative to the multi-year means. The 'Mean' and 'Max' in (a) and (b) are the annual mean and maximum VIs, respectively.

\subsection{Spatial differences in Global Vegetation Trends}



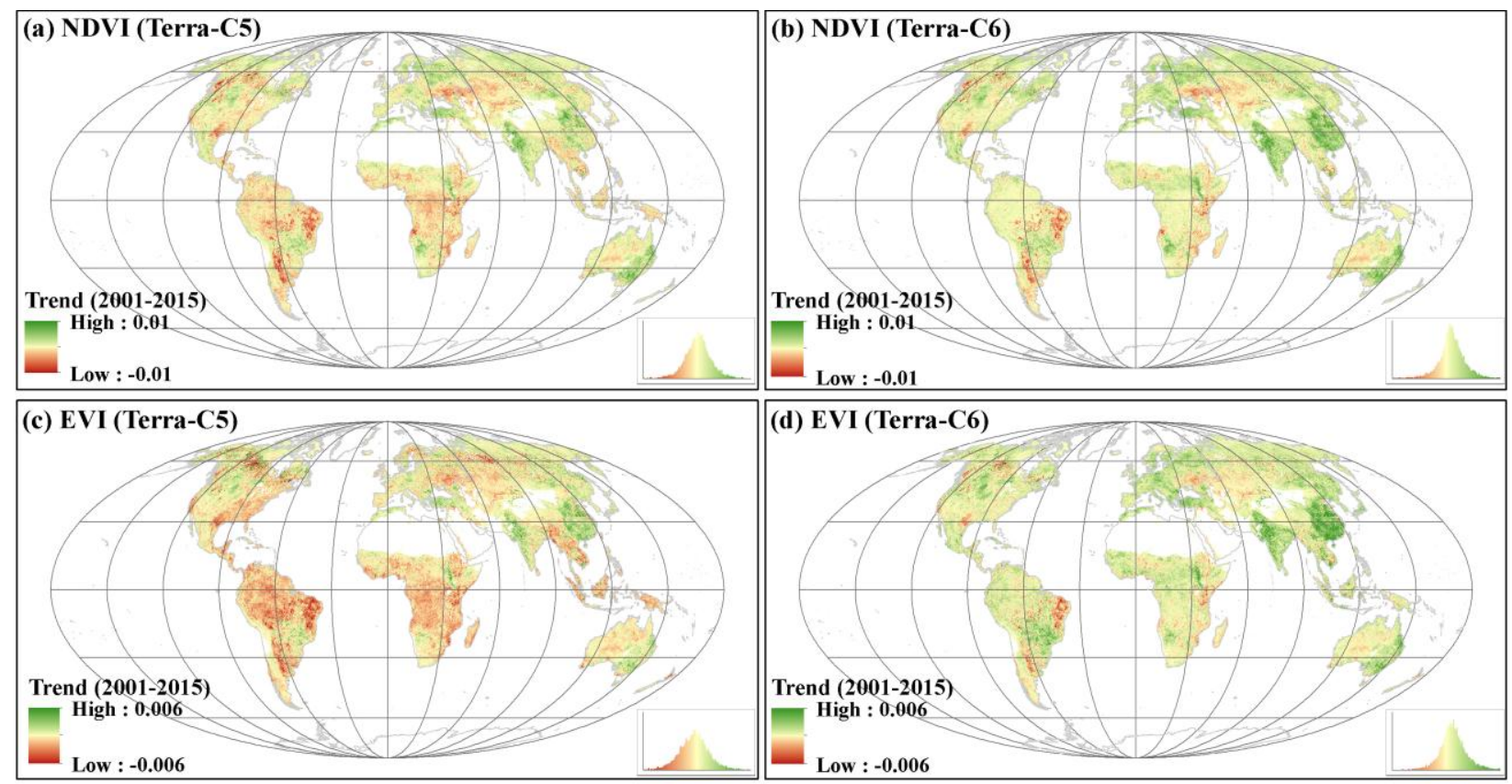

Fig. 4. Comparison of spatial patterns of linear trends in annual Terra NDVI (a, C5; b, C6) and EVI (c, C5; d, C6) from 2001 to 2015. Non-vegetated areas are masked out. The lower right side in each subfigure is the histogram of VI trend ( $\mathrm{X}$ axis is the VI trend; $\mathrm{Y}$ axis is the pixel count), which shares the same legend of subfigure.

Spatially, Terra-C5 and Terra-C6 showed dramatic differences in annual trends from either NDVI or EVI from 2001 to 2015 (Figs. 4 \& S1; Table 1). Annual NDVI from Terra-C5 showed decreasing trends over $48 \%$ of vegetated area $(11 \%$ significantly with $\mathrm{P}<0.05$; Table 1$)$. However, for Terra-C6, only $29 \%$ of the vegetated areas showed decreasing trends in annual NDVI (5\% significantly with $\mathrm{P}<0.05$; Table 1$)$. The large browning areas located in Congo Basin, Amazon, Indonesia, and eastern US seen in Terra-C5 NDVI (Fig. 4a) vanished in TerraC6 NDVI (Fig. 4b). On the contrary, parts of greening areas (e.g. central China and India) captured by Terra-C5 NDVI (Fig. 4a) became greener in Terra-C6 NDVI (Fig. 4b). Similar with NDVI, annual EVI also exhibited contrasting spatial patterns of linear trends between Terra-C5 
(i.e. large browning areas) and Terra-C6 (i.e. large greening areas) (Fig. 4c, d). Compared to NDVI (i.e. $48 \%$ of vegetated area; Table 1), annual EVI from Terra-C5 showed even larger browning areas (i.e. 60\%), especially in southeastern North America and vast tropical regions (Fig. 4a, c), while the areas with decreasing annual EVI trends from Terra-C6 are generally consistent (i.e. 28\%) with those based on Terra-C6 NDVI (i.e. 29\%).

The vast greening areas reflected in MODIS VIs from Terra-C6 were also seen in Aqua and GIMMS3g VIs (Figs. S2 \& S3; Table S2). During the overlap period (i.e. 2001 to 2013), MODIS NDVI from Aqua-C6 showed increasing trend over 59.6\% of vegetated area (12.1\% significantly with $\mathrm{p}<0.05)$, slightly higher than Aqua-C5 with increasing trend over $59.1 \%$ of area $(10.0 \%$ significantly with $\mathrm{p}<0.05)$, but slightly lower than Terra-C6 over $61.8 \%$ of area $(12.6 \%$ significantly with $\mathrm{p}<0.05)$. GIMMS NDVI showed significantly increasing trend $(\mathrm{P}<0.05)$ over $13.8 \%$ of total area, higher than the areas for other NDVIs (Table S2). The extra greening area reflected by GIMMS NDVI were mainly located in South America (Fig. S2). MODIS EVI from Aqua-C6 increased significantly $(\mathrm{p}<0.05)$ over $14.3 \%$ of total area, identical to Terra-C6, but slightly higher than Aqua-C5 (11.2\%) (Table S2). Overall, compared to the annual browning trends from Terra-C5 VIs, MODIS C6 VIs as well as Aqua-C5 and GIMMS3g VIs all showed significant greening trends. From C5 to C6, Terra-VIs (especially EVI) exhibited major shifts in the histograms of the annual trends (Fig. 5a, c), while Aqua-VIs showed relatively stable trend histograms (Fig. 5b, d). 

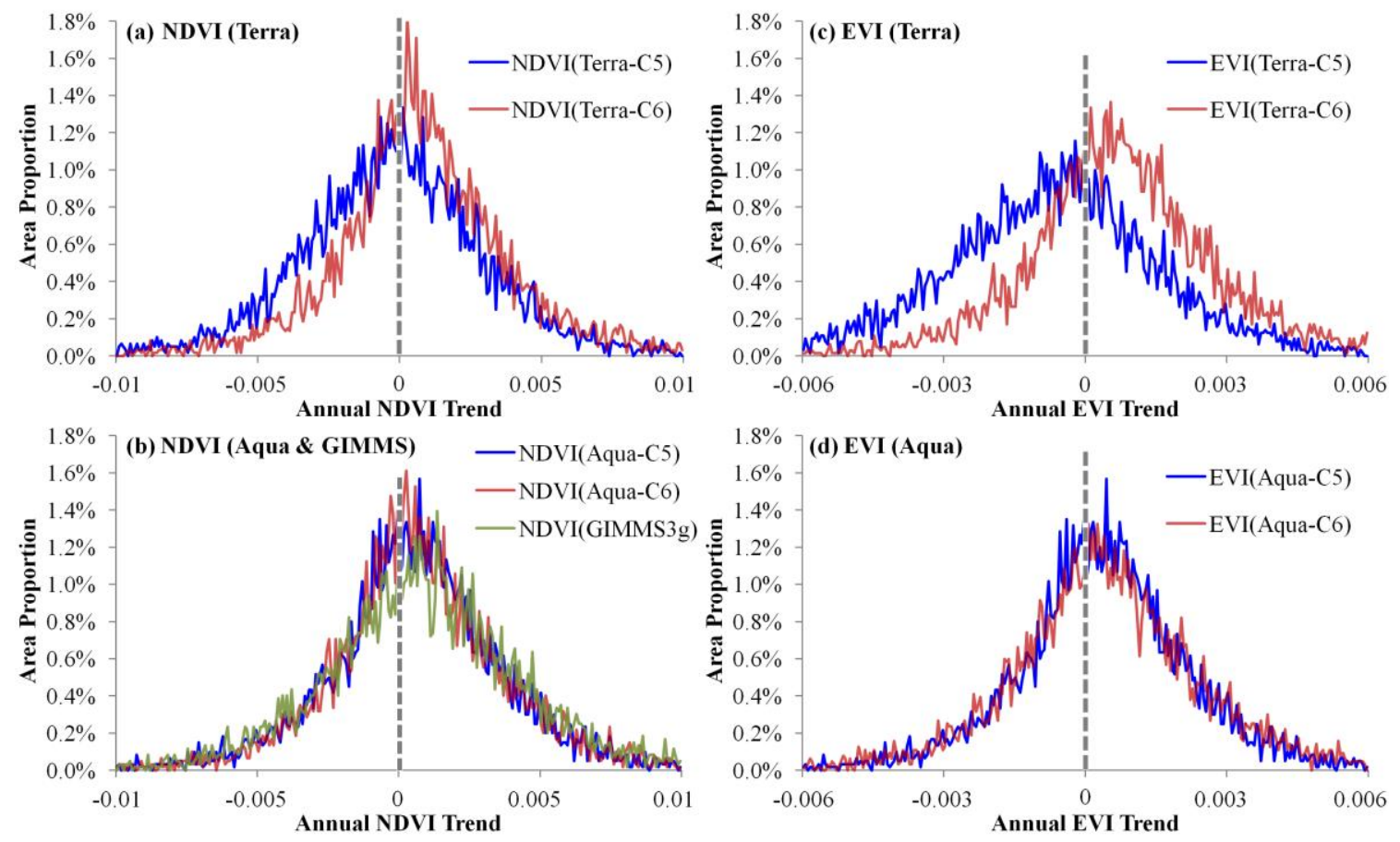

Fig. 5. Histograms of annual VI trends from Terra (a: NDVI; c: EVI), Aqua and GIMMS3g (b: NDVI; d: EVI) during the overlap period of 2003 to 2013. The area proportion on Y axis is based on the global vegetated area. The bin size of annual VI trend in each subfigure is the ratio of the entire range of values (i.e. 0.02 for NDVI; 0.012 for EVI) to the interval number of 256.

\subsection{Global Error Envelope in MODIS VI Trends}

Given Terra and Aqua provide two independent MODIS-VI products with consistent VI retrieval algorithms, we further compared their VI differences to evaluate the uncertainties in global vegetation trends. The VI difference between Terra and Aqua is also regarded as "Global Error Envelope" (GEE) in MODIS VI (Didan et al., 2016). During the study period, from C5 to C6, the maximum GEE for annual global NDVI decreased from 0.010 (or $2.4 \%$ ) to -0.005 (or $-1.2 \%$ ), while the maximum GEE for EVI dropped from 0.008 (or $2.9 \%$ ) to -0.001 (or $-0.4 \%$ ), respectively (Fig. 6). Annual global NDVI and EVI from MODIS-C6 were converged with the 
same sign of GEE in most years, except the year of 2003, 2011 and 2015 (Fig. 6). Overall, from C5 to C6, annual global NDVI and EVI trends during 2013 to 2015 showed improved GEEs from $-0.00086 \mathrm{yr}^{-1}$ to $0.0001 \mathrm{yr}^{-1}$, and from $-0.0011 \mathrm{yr}^{-1}$ to $0.0001 \mathrm{yr}^{-1}$, respectively.

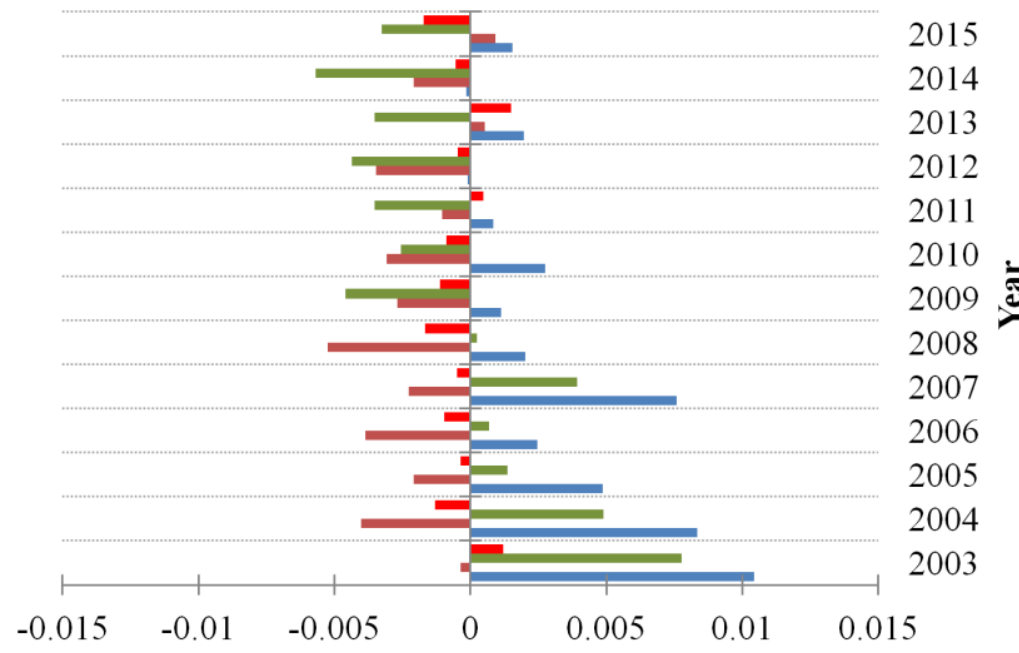

Annual global VI difference between Terra and Aqua

-EVI-C6(Terra-Aqua) =EVI-C5(Terra-Aqua)

- NDVI-C6(Terra-Aqua) - NDVI-C5(Terra-Aqua)

Fig. 6. Annual global MODIS-VI differences between Terra and Aqua from 2003 to 2015

Spatially, annual NDVI and EVI trends in MODIS-C5 showed wide distributions of large GEE with negative sign over the globe, especially in tropics and southeastern Asian (Fig. 7a, c). However, these dramatic GEE were largely reduced in annual NDVI and EVI trends in MODISC6 (Fig. 7a, c). More importantly, MODIS-C6 showed a much more equivalent distribution of GEE in annual VI trend (i.e. $50.0 \%$ and $49.4 \%$ of vegetated area for negative GEE in NDVI and EVI, respectively) when comparing with MODIS-C5 (i.e. $70.1 \%$ and $81.9 \%$ of vegetated area for negative GEE in NDVI and EVI, respectively) (Fig. 7). A small portion of tropical and boreal regions (i.e. $7.7 \%$ and $9.0 \%$ of vegetated area for NDVI and EVI, respectively) still showed relatively large GEE (i.e. $|\mathrm{GEE}|>0.003 \mathrm{yr}^{-1}$ and $|\mathrm{GEE}|>0.002 \mathrm{yr}^{-1}$ for NDVI and EVI, 
respectively) in annual VI trends in MODIS-C6 (Fig. 7). These areas were further confirmed to have lower VI correlations between Terra and Aqua (Fig. S4).



Fig. 7. Spatial patterns of annual VIs trend differences between Terra and Aqua (a: NDVI-C5; b: NDVI-C6; c: EVI-C5; d: EVI-C6). Annual trend of each MODIS-VI is calculated during the overlap period of 2003 to 2013, which can be seen in Figs. S2 \& S3. The lower right side in each subfigure is the histogram of VI trend difference ( $\mathrm{X}$ axis is the VI trend difference; $\mathrm{Y}$ axis is the pixel count), which shares the same legend of subfigure.

To test if MODIS-C6 had effectively removed the effect of sensor degradation spatially, we compared the annual EVI trends from Terra and Aqua over a vast desert area (Fig. 8). Annual EVI from Terra-C5 showed decreased trends over $85.8 \%$ of total area of this region (56.0\% significantly with $\mathrm{P}<0.05$ ) (Fig. 8a). However, the vast browning areas were not seen in TerraC6, which showed decreasing annual EVI trends only over $28.1 \%$ of total area (3.5\% significantly with $\mathrm{P}<0.05$ ) (Fig. 8b). It is worth noting that Aqua-C5 also showed a relative 
large area with decreasing annual EVI trends (68.1\%), of which 33.6\% showed significant trends with $\mathrm{P}<0.05$ (Fig. 8c). Similar with Terra-C6, Aqua-C6 showed limited browning area over this region $(32.0 \%$; 5.5\% significantly with $\mathrm{P}<0.05)$ (Fig. 8d). Overall, Terra-C5 showed wider extent and larger amplitude of decreased annual EVI than Aqua-C5, but the browning areas had considerably shrunk in Terra- and Aqua-C6 (Fig. 8). Interestingly, a small portion of greening area was both shown by Terra- and Aqua-C6, which were mainly distributed around the desert (Fig. 8b, d). It is not clear that these greening trends are caused by the temporal development of desert oasis, or influenced by other factors, such as flowing dunes.
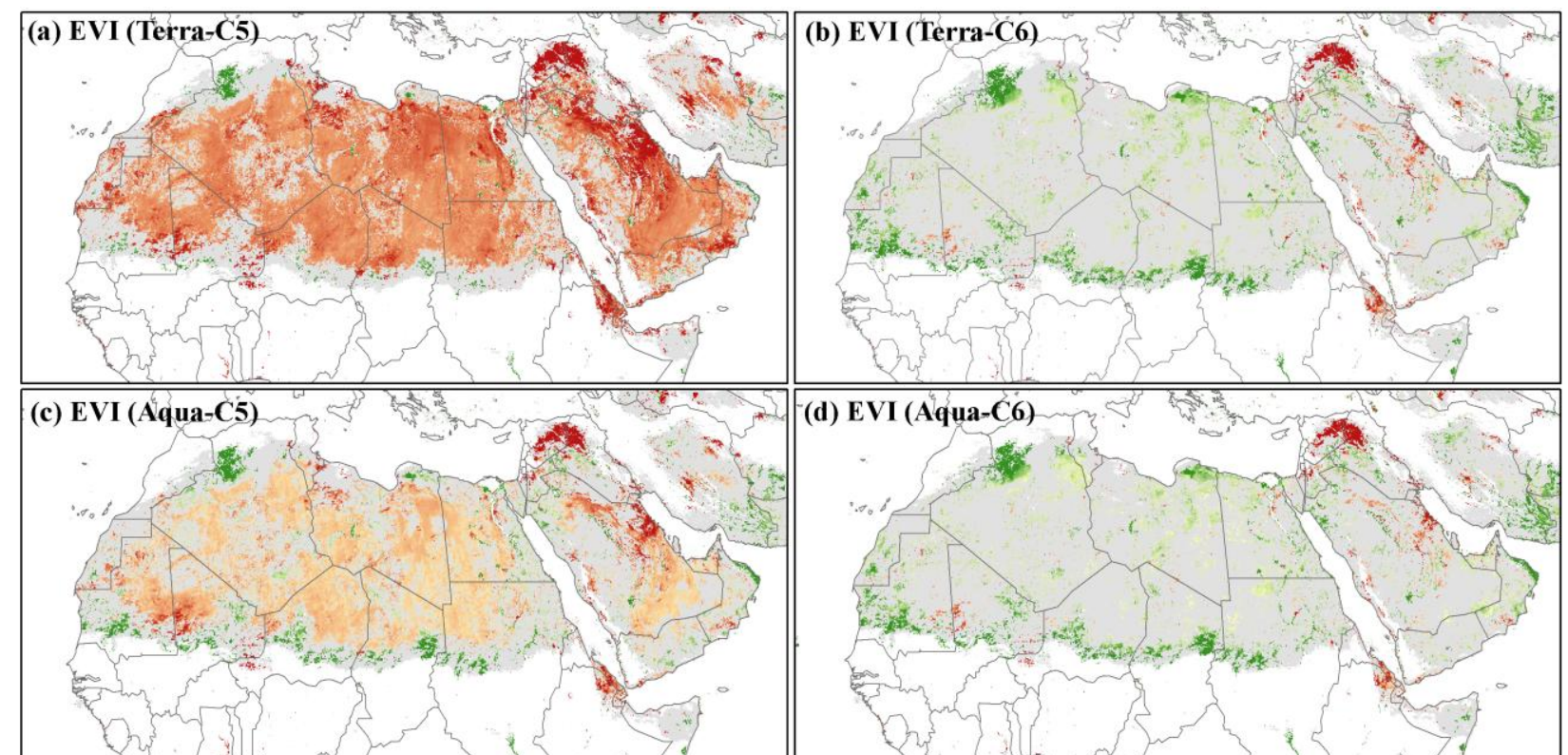

(d) EVI (Aqua-C6)

- $15 \%$


(2003-2013)

Fig. 8. Spatial patterns of annual EVI trend in Terra-C5 (a), Terra-C6 (b), Aqua-C5 (c) and Aqua-C6 (d) from 2003 to 2013. All vegetated area are masked out with white color. The gray color indicated the insignificant trend $(\mathrm{P}>0.05)$. The gray lines are the country boundaries.

\subsection{Climatic Sensitivity of Global Vegetation Trends}


We investigated the sensitivity of global vegetation to climate variations by conducting partial and multiple correlation analyses between annual EVI from Terra-C6 and three key climate factors (i.e. annual total radiation, mean temperature and total precipitation). Overall, climatic responses of global vegetation on the annual scale showed complex spatial patterns (Figs. $9 \&$ S5). Globally, $12.0 \%$ of vegetated area exhibited significant partial correlation $(\mathrm{P}<0.05)$ between annual EVI and total precipitation (Fig. 9c), followed by mean temperature (10.1\%; Fig. 9b), and total radiation (7.9\%; Fig. 9a). The greening trends in India, southeastern Australia, central North America, and South Sudan (Fig. S5a) were generally associated with a wetting trend (Fig. S5d). In contrast, the browning trends in western Asia, eastern Brazil, southwestern U.S., and Argentina (Fig. S5a) were closely linked with a drying trend (Fig. S5d). The vast greening regions in the high latitudes (e.g. northern Eurasian; Fig. S5a) were related to the increasing trends in temperature and radiation (Fig. S5b, c). Interestingly, a dimming (i.e. decreasing solar radiation reaching the land surface) but drying trend was associated with the substantial greening in the central and southern China (Fig. S5). Overall, according to multiple correlation analysis (Fig. 9d), climate variations explained over $50 \%$ of annual greenness variations over $19.7 \%$ of global vegetated area, which were mainly located in semi-arid and boreal regions; Less than $20 \%$ of annual greenness variations were explained by climate over $30.5 \%$ of vegetated area, which were mostly distributed in the tropical and temperate regions. 

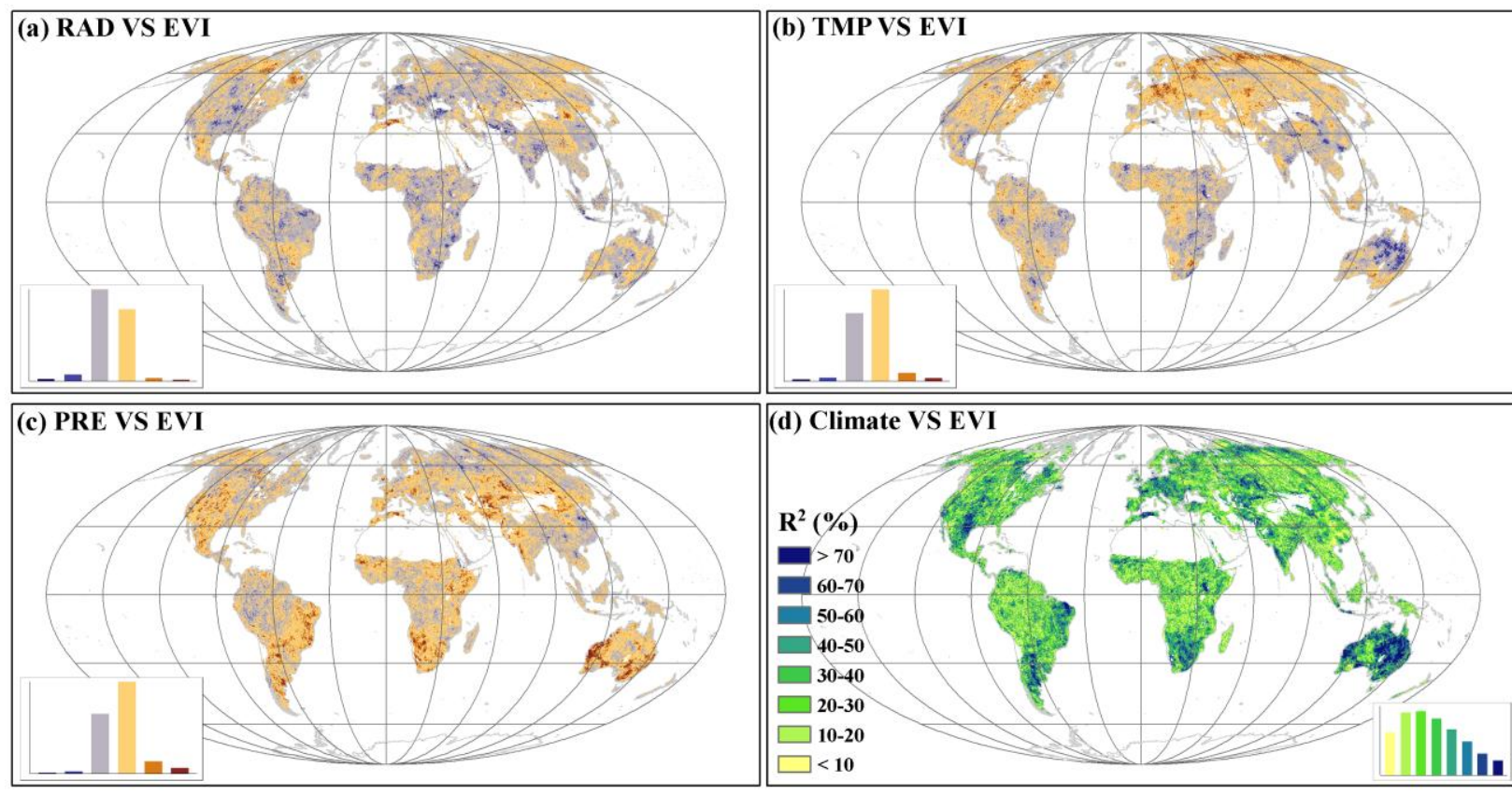

Partial Correlation (2001-2014)

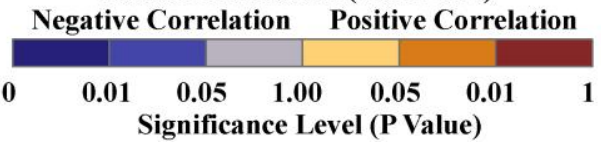

Fig. 9. Sensitivity of annual EVI from Terra-C6 to climate variations from 2001 to 2014. a c: partial correlations between annual EVI and (a) annual total radiation (RAD), (b) annual mean air temperature (TMP), and (c) annual total precipitation (PRE); d: square of multiple correlation (i.e. coefficient of determination, denoted $\mathrm{R}^{2}$ ) between annual EVI and all three climate factors (RAD, TMP and PRE). Non-vegetated areas are masked out. The lower side in each subfigure is the histogram of partial correlation $\left(\mathrm{a} \sim \mathrm{c}\right.$; left sides) or $\mathrm{R}^{2}$ ( $\mathrm{d}$; right side) (X axis is the partial correlation or $\mathrm{R}^{2}$; $\mathrm{Y}$ axis is the pixel count). Subfigures $(\mathrm{a}) \sim(\mathrm{c})$ share the same legend, which is placed below the figure. The t-test is used to calculate the significance level for partial correlation in $(\mathrm{a}) \sim(\mathrm{c})$.

\section{Discussion}


Our analysis based on MODIS VIs, especially EVI, from Terra-C5 indicated that global vegetation had browning trends over large areas (Figs. $2 \sim 5$; Tables $1 \& 2 \mathrm{~S}$ ). We believe that these trends are mainly results of sensor degradation as previously studies suggested (Lyapustin et al., 2014; Wang et al., 2012). Based on pseudo-invariant desert targets, Wang et al. (2012) estimated that the sensor degradation in MODIS Terra-C5 led to a 0.001-0.004 $\mathrm{yr}^{-1}$ decline in NDVI under a range of simulated aerosol conditions and surface types, and the negative MODIS-C5 NDVI trends derived from Terra (17.4\%) was nearly three times the area from Aqua (6.7\%) in North America during 2002 - 2010. Our analysis based on a desert site in Egypt also confirmed the similar sensor degradation-related decline trends in MODIS reflectance (Fig. 3c), thus EVI (Fig. 3d) for Terra-C5. Detsch et al. (2016) conducted a comparative study of crossproduct NDVI dynamics in a tropical region in Tanzania, and clearly identified the sensor degradation effect on the $250 \mathrm{~m}$ Terra-C5 NDVI. Due to the exposure to severe solar and cosmic radiation, Earth observing sensors begin to age as soon as they start in-orbit operations (Lyapustin et al., 2014). However, Terra MODIS showed a much faster sensor degradation than Aqua (Figs. 8, S2 \& S3; Table S2), probably because two extra events as identified by NASA engineers occurred to Terra, including a potential optics contamination in a prelaunch testing and an operation anomaly for solar diffuser door in the early post launch period, which could significantly accelerate the Terra sensor degradation (Lyapustin et al., 2014). Technical evaluations showed the sensor degradation of Terra-C5 is most pronounced in the blue band, and decreases with wavelength (Lyapustin et al., 2014; Wang et al., 2012). These studies could explain the larger areas with decreasing trends in annual EVI than NDVI from Terra-C5 (Figs. 2, $4 \& 5$; Table 1), given the blue band was included in the calculation of EVI (Huete et al., 2002). Compared to Terra, Aqua had much more consistent temporal trends in VIs between C5 and C6 
(Figs. 2, 5, S2 \& S3; Table S2). However, from C5 to C6, MODIS-Aqua still showed 0.03\% $\mathrm{yr}^{-1}$ and $0.11 \% \mathrm{yr}^{-1}$ increases in annual trends of global NDVI and EVI, respectively, during 2003 and 2015 (Figs. 2). Therefore, the sensor degradation had also impacted Aqua-C5 VIs, especially EVI (Lyapustin et al., 2014). Our annual EVI trend analysis over the desert areas further confirmed the presence of sensor degradation (Fig. 8b). It should be noted that compared to Aqua-C5, Aqua-C6 systematically showed higher values in NDVI (Fig. 2a), but lower values in EVI (Fig. 2b), which might be due to the adjustments of C6 VI algorithm (Didan et al., 2015).

In contrast to C5, MODIS-C6 VIs showed highly consistent annual trends and variations between Terra and Aqua (Figs. 2, 4, 7, S2 \& S3; Tables $1 \&$ S2), suggesting the improvements of product quality for MODIS-C6. Our site- and area-level analyses both confirmed that the potential sensor degradation-related decline trends were largely eliminated in MODIS-C6 products (Figs. $2 \&$ 8). Global NDVI from Terra- and Aqua-C6 generally matched the annual trends and variations with GIMMS3g (Figs. 2a, 4b \& S2), although the latter had a coarser spatial resolution, and substantially different sensor and retrieval algorithm (Pinzon and Tucker, 2014]. The distinct variations in GIMMS3g NDVI in the initial and last few years (Fig. 2a) may be due to the NOAA satellite sensor shifts (i.e. NOAA-16 to NOAA-17 in 2004; NOAA-17 to NOAA-18 in 2009) (Tian et al., 2015]). Globally, annual MODIS EVI showed larger greening areas (or smaller browning areas) than annual NDVI both for Terra- and Aqua-C6 (Figs. 5, S2 \& S3; Table S2). This difference may be caused by the different definitions of NDVI and EVI. Theoretically, MODIS EVI should be superior to NDVI in monitoring vegetation activities because of the correction for the remnant atmospheric and background contaminations (Huete et al., 2002). Interestingly, for MODIS-C6, annual EVI showed slightly more consistent spatial- 
temporal trends between Terra and Aqua than NDVI (Figs. 2, 6, S2 \& S3; Tables S2), suggesting the advantage of EVI over NDVI when using MODIS-C6 VI products.

We noted a positive change of annual global NDVI from Terra-C6 in 2015 relative to 2014, while other MODIS-C6 VIs showed negative changes (Figs. 2 \& 6). In NASA's recent MODIS/VIIRS Science Team Meeting, Vermote (2016) reported a systematic positive anomaly in Terra-C6 reflectance (including Red and NIR bands) after 2014 when compared with AquaC6. However, in our study, this positive abnormity in Terra-C6 was not found on the Egypt desert site (Fig. S6). On the contrary, this site showed slightly negative changes in Red, NIR and Blue reflectance (Fig. S6b), thus NDVI and EVI for Terra-C6 (Fig. S6a). Additional analysis based on a vast desert area did not support the existence of the systematic positive abnormity either (Fig. S7a, b). Seasonal analysis showed that the positive change of annual global NDVI from Terra-C6 in 2015 was attributable to the increased NDVI in the growing season (Fig. S7c, d). However, our spatial analysis based on annual maximum VIs did not identify a clear tendency of the positive anomaly in Terra-C6 NDVI on the spatial scale when comparing with other MODIS-C6 VIs (Figs. S8 \& S9). To examine the positive change of annual global NDVI from Terra-C6 in 2015, we selected a grass site (34.25N, $-89.87 \mathrm{~W})$ in southern US where showed the similar positive change in annual Terra-C6 NDVI, but negative change in annual Terra-C6 EVI (Fig. S10). On this site, monthly NDVI and EVI anomalies in 2015 relative to 2014 showed small irregular discrepancies, which were accumulated to dominate the anomaly difference on the annual scale (Fig. S10). While annual global NDVI from Terra-C6 showed positive change in 2015, its long-term trend during the study period was still lower than that in annual global EVI from Terra-C6 (Table 1). 
Based on the updated MODIS EVI from Terra-C6, our study showed a significant greening trend in global vegetation during the past 15 years, supporting the recent findings of the enhanced land carbon sink by the Global Carbon Project (Fig. 12; Quéré et al., 2015), as well as other studies (Ahlström et al., 2015; Ballantyne et al., 2012). Therefore, many previous studies based on MODIS Terra-C5 products analyzing temporal trend may need to be reanalyzed using the C6 data to clarify our understanding of vegetation dynamics. For example, Zhao and Running (2010, 2011) reported a drought-induced decline in terrestrial gross and net primary productivity (GPP and NPP) from 2000 through 2009 based on Terra-C5 data. Guay et al. (2014) conducted a multi-sensor satellite data assessment on vegetation activity patterns at high northern latitudes, and surprisingly found that the growing season NDVI derived from MODIS-C5 Nadir BRDFAdjusted Surface Reflectance (NBAR) data showed a declining trend from 2001 to 2011, opposite to the increasing trends in all other satellite data. Tian et al. (2015) evaluated the temporal consistency of several long-term global NDVI datasets, and found a major annual trend difference in seasonal NDVI between Terra-C5 (i.e. downward trend) and Aqua-C5 (upward trend). These findings may be likely influenced or caused by the sensor degradation of MODISC5 products (Lyapustin et al., 2014). On the contrary, Anav et al. (2015) reviewed seven process-based land ecosystem models that do not involve MODIS data, and found all models showed an increasing trend of terrestrial global GPP since 2000. They further examined the longterm eddy covariance flux towers since 1997, and found that 14 of 16 sites showed upward trends in annual growing season GPP (June - August). Their conclusion about the enhanced global vegetation activity was consistent with our analysis based on the new MODIS-C6 VIs. 
Spatially, large browning areas in tropical region shown in Terra-C5 VIs were not seen in TerraC6 data (Fig. 4). Based on Terra-C5 LAI/FPAR products, Zhao and Running $(2010,2011)$ indicated that the warm-induced drying trends caused the annual GPP and NPP declines from 2000 to 2009 in Amazon and East Asia rainforests. Based on Terra-C5 VIs, Zhou et al. (2014) reported a widespread decline of rainforest greenness in Congo Basin in the past decade, and linked it with a persistent long-term drying trend there. These studies based on Terra-C5 data might have suffered from sensor degradation (Lyapustin et al., 2014) and overstated the sensitivity of tropical vegetation to drought. Our partial correlation analysis based on Terra-C6 EVI showed that the tropical rainforests, especially in Amazon and Congo, were insensitive to precipitation (Fig. 4c). In contrast, most semi-arid areas showed strong associations with precipitation based on Terra-C6 (Fig. 4c), which is consistent with the study from Ahlström et al. (2015). During the study period, the boreal region, based on Terra-C6, showed extensive greening trend that mainly related to the warming and increased radiation (Figs. 9a, b, S2 \& S5), which is consistent with a recent study on enhanced plant productivity in northern ecosystems (Forkel et al., 2016).

Our multiple correlation analysis based on Terra-C6 EVI showed stronger climate impacts in boreal and arid regions than in the tropical and temperate areas (Fig. 9d). However, a recent study from Seddon et al. (2016), who developed a new vegetation sensitivity index using monthly Terra-C5 MODIS EVI and three MODIS-derived climate variables, showed a different climate sensitivity pattern with higher sensitivity for tropical rainforests, but lower sensitivity for vast semi-arid ecosystems. Although long-term linear trends were de-trended in their MODISbased monthly data, their results may still be influenced by the sensor degradation in Terra-C5 
given the possible non-linear degradation rate. In fact, the de-trended annual global EVI showed poor correlation between Terra-C5 and -C6 from 2001 to 2015 ( $R=0.33, \mathrm{P}=0.23$; Fig. 2b). Another reason for the difference may be related to different temporal scales chosen by Seddon et al. (2016) (i.e. seasonal) and our study (i.e. annual). The vegetation dynamics that could not be explained by climate variations may be related to other factors, e.g., natural or anthropogenic disturbances, plant regrowth and succession, $\mathrm{CO}_{2}$ fertilization, nitrogen deposition, etc (Chapin III et al., 2011; Zhu et al., 2016). During the study period, albeit a drying and dimming climate, the central and southern China exhibited widespread greening trends, which may be caused by the comprehensive afforestation and forest protection programs carried out since 2000 (Piao et al., 2015; Zhang et al., 2014).

From C5 to C6, the multi-year averaged global NDVI increased $0.4 \%$ and $2.0 \%$ for Terra and Aqua, respectively, while EVI decreased 1.5\% for both Terra and Aqua (Table S2), indicating the significant adjustments of MODIS VIs. Currently, a number of ecosystem models are calibrated based on MODIS VIs from C5 or even older collections, these models may need to be re-calibrated to avoid systematic errors if using MODIS C6 data (Song et al., 2013). Using the MAIAC (multiage implementation of atmospheric correction) -based spectral reflectance, Lyapustin et al. (2014) showed that an enhanced C6+, which had compensated for the increased polarization sensitivity of MODIS Terra since about 2007, could remove an additional slightly negative trend in Terra-C6 NDVI from a MODIS tile in Georgia, US. However, based on our global evaluation, although Terra- and Aqua-C6 showed much more spatial-temporal consistencies in VIs (Figs. 2, 5, 7, S2 \& S3), Terra-C6 still tended to show slightly larger trends in both NDVI and EVI than Aqua-C6 (Fig. 5; Table S2). Long-term trends in monthly VIs over 
desert site also confirmed it (Fig. S11). This could be because the morning orbit of Terra gets more cloud-free observations than the afternoon orbit of Aqua (Lyapustin et al., 2014). However, it is worth noting that uncertainties from calibrations, residual clouds, poor aerosol correction, as well as poor representation of BRDF are further involved in both Terra- and Aqua-C6 products (Didan et al., 2016). Our analysis based on GEE also showed potential discrepancies still exist (Fig. 6), especially in tropical and boreal regions (Fig. 7). While the improvements of MODISC6 VIs for Terra and Aqua with better convergence will continue, the enhanced global vegetation activity revealed in our study has profound implications for past studies based on MODIS-C5 VI products. More importantly, an ongoing greening Earth identified by MODIS-C6 may suggest a positive feedback of vegetation under global environmental change (Nemani et al., 2003; Zhu et al., 2016).

\section{Conclusions}

This study comprehensively compared MODIS-C5 and -C6 VI products from both Terra and Aqua satellites for the time period of 2000-2015. We found that global vegetation showed a remarkable greening trend in the past 15 years based on MODIS-C6 VIs. Spatially, large portion of browning areas in tropical regions previously identified by Terra-C5 VIs might be spurious due to sensor degradation. The widespread greening areas shown by Terra-C6 VIs were further confirmed by Aqua-C6 and GIMMS3g VIs. We found stronger association between the climate and vegetation in the boreal and arid regions than other areas based on Terra-C6 EVI. A greening globe as revealed by MODIS-C6 VIs from this new analysis is consistent with the recent literature reports of enhanced land carbon sink. Previous studies based on MODIS Terra-C5 VI products may need to be re-analyzed in order to more accurately represent the true conditions of 
the Earth. Our new analysis contributes to better understanding the role of vegetation in regulating the Earth's biogeochemical and climatic systems.

\section{Acknowledgements}

We acknowledged NASA's MODIS Science Team to provide Terra and Aqua MODIS-C5 and C6 VIs data, NASA Earth Exchange platform to provide GIMMS3g NDVI, Global Carbon Project Science Team to provide the land carbon budget data, and Dr. Nicolas Viovy to provide the global CRU-NCEP climate data. This research was financially supported by the US National Science Foundation (DEB-1313756) and Natural Science Foundation of China (31528004).

\section{References}

Ahlström, A., M. R. Raupach, G. Schurgers, B. Smith, A. Arneth, M. Jung, M. Reichstein, J. G. Canadell, P. Friedlingstein, and A. K. Jain (2015), The dominant role of semi-arid ecosystems in the trend and variability of the land CO2 sink, Science, 348(6237), 895-899.

Anav, A., P. Friedlingstein, C. Beer, P. Ciais, A. Harper, C. Jones, G. Murray-Tortarolo, D. Papale, N. C. Parazoo, and P. Peylin (2015), Spatiotemporal patterns of terrestrial gross primary production: A review, Rev. Geophys., 53, 785-818, doi:10.1002/2015RG000483.

Arneth, A., S. P. Harrison, S. Zaehle, K. Tsigaridis, S. Menon, P. J. Bartlein, J. Feichter, A. Korhola, M. Kulmala, and D. O'donnell (2010), Terrestrial biogeochemical feedbacks in the climate system, Nature Geoscience, 3(8), 525-532.

Baldocchi, D., E. Falge, L. Gu, R. Olson, D. Hollinger, S. Running, P. Anthoni, C. Bernhofer, K. Davis, and R. Evans (2001), FLUXNET: a new tool to study the temporal and spatial 
variability of ecosystem-scale carbon dioxide, water vapor, and energy flux densities, Bulletin of the American Meteorological Society, 82(11), 2415-2434.

Ballantyne, A., C. Alden, J. Miller, P. Tans, and J. White (2012), Increase in observed net carbon dioxide uptake by land and oceans during the past 50 years, Nature, 488(7409), 70-72.

Carlson, T. N., and D. A. Ripley (1997), On the relation between NDVI, fractional vegetation cover, and leaf area index, Remote Sens. Environ., 62(3), 241-252.

Chapin III, F. S., P. A. Matson, and P. Vitousek (2011), Principles of terrestrial ecosystem ecology, Springer Science \& Business Media.

Cramer, W., A. Bondeau, F. I. Woodward, I. C. Prentice, R. A. Betts, V. Brovkin, P. M. Cox, V. Fisher, J. A. Foley, and A. D. Friend (2001), Global response of terrestrial ecosystem structure and function to $\mathrm{CO} 2$ and climate change: results from six dynamic global vegetation models, Global Change Biol., 7(4), 357-373.

Cohen, J., Cohen, P., West, S.G., \& Aiken, L.S. (2013). Applied multiple regression/correlation analysis for the behavioral sciences. Lawrence Eribaum Associates, Inc., Publishers, New Jersey, USA

Detsch, F., Otte, I., Appelhans, T., \& Nauss, T. (2016). A Comparative Study of Cross-Product NDVI Dynamics in the Kilimanjaro Region-A Matter of Sensor, Degradation Calibration, and Significance. Remote Sensing, 8, 159

Didan, K. (2010), Multi-satellite earth science data record for studying global vegetation trends and changes, paper presented at Proceedings of the 2010 international geoscience and remote sensing symposium, Honolulu, HI, USA. 
Didan, K., A. B. Munoz, C. Tucker, and J. Pinzon (2016). Vegetation Indices Climate Signals and Error Bars \& Transition to VIIRS, MODIS/VIIRS Science Team Meeting. Silver Spring, MD, USA (June 6-10, 2016). https://modis.gsfc.nasa.gov/sci_team/meetings/

Didan, K., A. B. Munoz, R. Solano, and A. Huete (2015), MODIS Vegetation Index User's Guide (MOD13 Series) Version 3.00 (Collection 6), Vegetation Index and Phenology Lab, The University of Arizona, https://vip.arizona.edu/.

Djavidnia, S., F. Mélin, and N. Hoepffner (2010), Comparison of global ocean colour data records, Ocean Sci., 6(1), 61-76.

Falkowski, P., R. Scholes, E. Boyle, J. Canadell, D. Canfield, J. Elser, N. Gruber, K. Hibbard, P. Högberg, and S. Linder (2000), The global carbon cycle: a test of our knowledge of earth as a system, science, 290(5490), 291-296.

Fensholt, R., and S. R. Proud (2012), Evaluation of earth observation based global long term vegetation trends - Comparing GIMMS and MODIS global NDVI time series, Remote Sens. Environ., 119, 131-147.

Forkel, M., N. Carvalhais, C. Rödenbeck, R. Keeling, M. Heimann, K. Thonicke, S. Zaehle, and M. Reichstein (2016), Enhanced seasonal CO2 exchange caused by amplified plant productivity in northern ecosystems, Science. DOI:10.1126/science.aac4971

Guay, K.C., Beck, P.S., Berner, L.T., Goetz, S.J., Baccini, A., \& Buermann, W. (2014). Vegetation productivity patterns at high northern latitudes: a multi-sensor satellite data assessment. Global Change Biology, 20, 3147-3158

Huete, A., C. Justice, and W. Van Leeuwen (1999), MODIS vegetation index (MOD13), Algorithm theoretical basis document, 3, 213. 
Huete, A., H. Liu, K. v. Batchily, and W. Van Leeuwen (1997), A comparison of vegetation indices over a global set of TM images for EOS-MODIS, Remote Sens. Environ., 59(3), 440451.

Huete, A., K. Didan, T. Miura, E. P. Rodriguez, X. Gao, and L. G. Ferreira (2002), Overview of the radiometric and biophysical performance of the MODIS vegetation indices, Remote Sens. Environ., 83(1), 195-213.

Law, B., E. Falge, L. v. Gu, D. Baldocchi, P. Bakwin, P. Berbigier, K. Davis, A. Dolman, M. Falk, and J. Fuentes (2002), Environmental controls over carbon dioxide and water vapor exchange of terrestrial vegetation, Agricultural and Forest Meteorology, 113(1), 97-120.

Levy, R. C., L. A. Remer, R. G. Kleidman, S. Mattoo, C. Ichoku, R. Kahn, and T. Eck (2010), Global evaluation of the Collection 5 MODIS dark-target aerosol products over land, Atmospheric Chemistry and Physics, 10(21), 10399-10420.

Lyapustin, A., Y. Wang, X. Xiong, G. Meister, S. Platnick, R. Levy, B. Franz, S. Korkin, T. Hilker, and J. Tucker (2014), Scientific impact of MODIS C5 calibration degradation and C6+ improvements. Atmos. Meas. Tech., 7, 4353-4365. doi:10.5194/amt-7-4353-2014

Maisongrande, P., B. Duchemin, and G. Dedieu (2004), VEGETATION/SPOT: an operational mission for the Earth monitoring; presentation of new standard products, Int. J. Remote Sens., 25(1), 9-14.

Marshall, M., E. Okuto, Y. Kang, E. Opiyo, and M. Ahmed (2016), Global assessment of Vegetation Index and Phenology Lab (VIP) and Global Inventory Modeling and Mapping Studies (GIMMS) version 3 products, Biogeosciences, 13(3), 625-639. 
Nemani, R.R., Keeling, C.D., Hashimoto, H., Jolly, W.M., Piper, S.C., Tucker, C.J., Myneni, R.B., \& Running, S.W. (2003). Climate-driven increases in global terrestrial net primary production from 1982 to 1999. Science, 300, 1560-1563

Pedelty, J., S. Devadiga, E. Masuoka, M. Brown, J. Pinzon, C. Tucker, D. Roy, J. Ju, E. Vermote, and S. Prince (2007), Generating a long-term land data record from the AVHRR and MODIS instruments, paper presented at Geoscience and Remote Sensing Symposium, 2007. IGARSS 2007. IEEE International, IEEE.

Piao, S., G. Yin, J. Tan, L. Cheng, M. Huang, Y. Li, R. Liu, J. Mao, R. B. Myneni, and S. Peng (2015), Detection and attribution of vegetation greening trend in China over the last 30 years, Global Change Biol., 21(4), 1601-1609.

Pinzon, J. E., and C. J. Tucker (2014), A non-stationary 1981-2012 AVHRR NDVI3g time series, Remote Sensing, 6(8), 6929-6960.

Quéré, C. L., R. Moriarty, R. Andrew, J. Canadell, S. Sitch, J. Korsbakken, P. Friedlingstein, G. Peters, R. Andres, and T. Boden (2015), Global Carbon Budget 2015, Earth System Science Data, 7, 349-396.

Rouse, J. W., R. Haas, J. Schell, and D. Deering (1974), Monitoring vegetation systems in the Great Plains with ERTS, NASA special publication, 351, 309.

Running, S. W., R. R. Nemani, F. A. Heinsch, M. Zhao, M. Reeves, and H. Hashimoto (2004), A continuous satellite-derived measure of global terrestrial primary production, Bioscience, $54(6), 547-560$.

Seddon, A. W., M. Macias-Fauria, P. R. Long, D. Benz, and K. J. Willis (2016), Sensitivity of global terrestrial ecosystems to climate variability, Nature, 531(7593), 229-232. 
Sitch, S., C. Huntingford, N. Gedney, P. Levy, M. Lomas, S. Piao, R. Betts, P. Ciais, P. Cox, and P. Friedlingstein (2008), Evaluation of the terrestrial carbon cycle, future plant geography and climate-carbon cycle feedbacks using five Dynamic Global Vegetation Models (DGVMs), Global Change Biol., 14(9), 2015-2039.

Song, C., M. P. Dannenberg, and T. Hwang (2013), Optical remote sensing of terrestrial ecosystem primary productivity, Progress in Physical Geography, 37(6), 834-854.

Tarnavsky, E., S. Garrigues, and M. E. Brown (2008), Multiscale geostatistical analysis of AVHRR, SPOT-VGT, and MODIS global NDVI products, Remote Sens. Environ., 112(2), 535-549.

Tian, F., R. Fensholt, J. Verbesselt, K. Grogan, S. Horion, and Y. Wang (2015), Evaluating temporal consistency of long-term global NDVI datasets for trend analysis, Remote Sens. Environ., 163, 326-340.

Tucker, C. J. (1979), Red and photographic infrared linear combinations for monitoring vegetation, Remote Sens. Environ., 8(2), 127-150.

Tucker, C. J., J. E. Pinzon, M. E. Brown, D. A. Slayback, E. W. Pak, R. Mahoney, E. F. Vermote, and N. El Saleous (2005), An extended AVHRR 8-km NDVI dataset compatible with MODIS and SPOT vegetation NDVI data, Int. J. Remote Sens., 26(20), 4485-4498.

Vermote, E. (2016). MODIS/VIIRS Surface Reflectance, MODIS/VIIRS Science Team Meeting. Silver Spring, MD, USA (June 6-10, 2016). https://modis.gsfc.nasa.gov/sci_team/meetings/ Wang, D., D. Morton, J. Masek, A. Wu, J. Nagol, X. Xiong, R. Levy, E. Vermote, and R. Wolfe (2012), Impact of sensor degradation on the MODIS NDVI time series, Remote Sens. Environ., 119, 55-61. 
Xu, L., A. Samanta, M. H. Costa, S. Ganguly, R. R. Nemani, and R. B. Myneni (2011), Widespread decline in greenness of Amazonian vegetation due to the 2010 drought, Geophys. Res. Lett., 38(7).

Zhang, Y., C. Song, K. Zhang, X. Cheng, L. E. Band, and Q. Zhang (2014), Effects of land use/land cover and climate changes on terrestrial net primary productivity in the Yangtze River Basin, China, from 2001 to 2010, Journal of Geophysical Research: Biogeosciences, $119(6), 1092-1109$.

Zhao, M., and S. W. Running (2010), Drought-induced reduction in global terrestrial net primary production from 2000 through 2009, science, 329(5994), 940-943.

Zhao, M., and S. W. Running (2011), Response to comments on "Drought-induced reduction in global terrestrial net primary production from 2000 through 2009”, Science, 333(6046), 10931093.

Zhou, L., Y. Tian, R. B. Myneni, P. Ciais, S. Saatchi, Y. Y. Liu, S. Piao, H. Chen, E. F. Vermote, and C. Song (2014), Widespread decline of Congo rainforest greenness in the past decade, Nature, 509(7498), 86-90.

Zhu, Z., S. Piao, R. B. Myneni, M. Huang, Z. Zeng, J. G. Canadell, P. Ciais, S. Sitch, P. Friedlingstein, and A. Arneth (2016). Greening of the Earth and its drivers. Nature Climate Change. doi:10.1038/nclimate300 


\section{Figure Captions:}

Fig. 1. Spatial patterns of data quality for Terra-C5 and Terra-C6 in 2007. (a) (b): month counts on Terra-C5 (a) and Terra-C6 (b) with monthly NDVI > 0; (c) (d): month counts on Terra-C5 (c) and Terra-C6 (d) with monthly NDVI/EVI filled by historic data due to bad quality. Non-vegetated area are masked out. The gray background in (c) and (d) indicate the vegetated area. The summary statistics is seen in Table S1.

Fig. 2. Comparisons of annual changes of global average NDVI (a) and EVI (b) over vegetated area from 2001 to 2015 among MODIS products. Annual GIMMS3g NDVI and land carbon sink from global carbon budget were included in (a) and (b), respectively.

Fig. 3. Comparisons between Terra-C5 and Terra-C6 in inter-annual trends of global averaged maximum NDVI (a) and EVI (b), and monthly surface reflectance (c) and EVI (d) at a desert site in Egypt from 2001 to 2015. The annual anomalies in (a) and (b) are relative to the multi-year means. The 'Mean' and 'Max' in (a) and (b) are the annual mean and maximum VIs, respectively.

Fig. 4. Comparison of spatial patterns of linear trends in annual Terra NDVI (a, C5; b, C6) and EVI (c, C5; d, C6) from 2001 to 2015. Non-vegetated areas are masked out. The lower right side in each subfigure is the histogram of VI trend ( $\mathrm{X}$ axis is the VI trend; Y axis is the pixel count), which shares the same legend of subfigure.

Fig. 5. Histograms of annual VI trends from Terra (a: NDVI; c: EVI), Aqua and GIMMS3g (b: NDVI; d: EVI) during the overlap period of 2003 to 2013. The area proportion on $\mathrm{Y}$ axis is based on the global vegetated area. The bin size of annual VI trend in each subfigure is the ratio of the entire range of values (i.e. 0.02 for NDVI; 0.012 for EVI) to the interval number of 256.

Fig. 6. Annual global MODIS-VI differences between Terra and Aqua from 2003 to 2015 
Fig. 7. Spatial patterns of annual VIs trend differences between Terra and Aqua (a: NDVI-C5; b: NDVI-C6; c: EVI-C5; d: EVI-C6). Annual trend of each MODIS-VI is calculated during the overlap period of 2003 to 2013, which can be seen in Figs. S2 \& S3. The lower right side in each subfigure is the histogram of VI trend difference (X axis is the VI trend difference; $\mathrm{Y}$ axis is the pixel count), which shares the same legend of subfigure.

Fig. 8. Spatial patterns of annual EVI trend in Terra-C5 (a), Terra-C6 (b), Aqua-C5 (c) and Aqua-C6 (d) from 2003 to 2013. All vegetated area are masked out with white color. The gray color indicated the insignificant trend $(\mathrm{P}>0.05)$. The gray lines are the country boundaries.

Fig. 9. Sensitivity of annual EVI from Terra-C6 to climate variations from 2001 to 2014. a c: partial correlations between annual EVI and (a) annual total radiation (RAD), (b) annual mean air temperature (TMP), and (c) annual total precipitation (PRE); d: square of multiple correlation (i.e. coefficient of determination, denoted $\mathrm{R}^{2}$ ) between annual EVI and all three climate factors (RAD, TMP and PRE). Non-vegetated areas are masked out. The lower side in each subfigure is the histogram of partial correlation $\left(\mathrm{a} \sim \mathrm{c}\right.$; left sides) or $\mathrm{R}^{2}$ ( $\mathrm{d}$; right side) (X axis is the partial correlation or $\mathrm{R}^{2}$; $\mathrm{Y}$ axis is the pixel count). Subfigures $(\mathrm{a}) \sim(\mathrm{c})$ share the same legend, which is placed below the figure. The t-test is used to calculate the significance level for partial correlation in $(\mathrm{a}) \sim(\mathrm{c})$. 